\title{
Electron microscopy analysis of biofilms produced by Staphylococcus aureus exposed to UV-light on the surface of $\mathrm{SnO}_{2}$ thin films
}

Hazel Jaynelle Morales-Rodriguez ${ }^{1}$, Javier Camarillo-Cisneros ${ }^{2}$, María Alejandra Favila-Pérez ${ }^{2}$, Alva Rocío Castillo-González ${ }^{2}$, Celia María Quiñonez-Flores ${ }^{2}$, César Leyva-Porras ${ }^{3}$ and Carlos Arzate-Quintana ${ }^{2}$

${ }^{1}$ Universidad Tecnológica de Chihuahua Sur, Chihuahua, Chihuahua, Mexico, ${ }^{2}$ Facultad de Medicina y CienciasBiomédicas de la Universidad Autónoma de Chihuahua, Chihuahua, Chihuahua, Mexico, ${ }^{3}$ Centro de investigaciónenmaterialesavanzados (CIMAV), Chihuahua, Chihuahua, Mexico

Introduction

As an $\mathrm{n}$ - type wide band gap semiconductor $(\mathrm{Eg}=3.6 \mathrm{eV}) \mathrm{SnO}_{2}$ is one of the most intensively studied materials owing to its technological applications. The anomalous variation in the size and shape dependent properties of tin oxide nanoparticles makes it a promising candidate in optoelectronics, sensing, laser, solar cell, photocatalytic and biological applications. The photocatalyst material plays a crucial role to perform an effective photocatalytic reaction, and therefore its selection should be done carefully to fulfill both, appropriate electronic structure and reasonable energy of light for its photoactivation as the rate of the photocatalytic reaction is independent of the "active site". The antimicrobial efficiency of metal oxide nanoparticles depends on the particle size, presence of light, composition of aqueous medium used in assay etc. Electrostatic interactions are responsible for the attachment of nanoparticles to the bacteria. These interactions changes the integrity of cell membrane of bacteria and toxic free radicals are released which induce oxidative stress on bacteria [1]. Since antibiotic-resistant bacteria strains have become a serious health problem worldwide, it is a priority to develop new antimicrobial treatments that are not classified as antibiotics, and nanotechnology could be a valid alternative to revert this tendency [5].

Materials and Methods

Synthesis of $\mathrm{SnO}_{2}$ thin films were performed by the spray pyrolysis method by addition of Tin chloride to an $80^{\circ} \mathrm{C}$ heated glass surface (slides). Thin films characterization was performed by X-Ray diffraction, SEM (JSM-5800LV) microscopy and EDS (results reported in previous publication)[2]. Staphylococcus aureus ATCC 29213 was stored in Brain-Heart infusion until use in antimicrobial assays. Before the assays, a bacterial solution containing $2 \times 10^{7}$ bacteria/ml was prepared in distilled water used in the inoculation of $\mathrm{SnO} 2$ films by adding a $10 \mu \mathrm{l}$ drop on the surface. Two groups of samples were then classified: a control group with no exposure to UV light, and a group exposed to 60 minutes to $254 \mathrm{~nm}$ UV light. In order to allow biofilm formation, thin films were then stored 14 days at room temperature until SEM analysis.

Results

UV-light treatment was effective in eliminating S. aureus from the surface of the $\mathrm{SnO}_{2}$ thin films thanks to the photocatalysis of this semiconductive material, this result is supported by previous studies that concluded that this kind of material has a good antimicrobial activity, especially when exposed to UV radiation [3, 4, 6]. Micrographs in Figure 1 shows the reduction of organic material when a comparison is made between the films without treatment (Fig. 1A) and after 60 minutes of exposition (Fig. 1B). As mentioned before, biofilms are a virulence factor that protects bacterial cells from adverse environments, and help pathogenic bacteria to spread and cause infections. Such structures are present only in control samples (Fig. 2), however this kind of cells agglomerates are no longer detectable after the UV treatment. These results suggest that photocatalytic materials are promising disinfection methods that could be applied to a wide variety of microorganisms. 

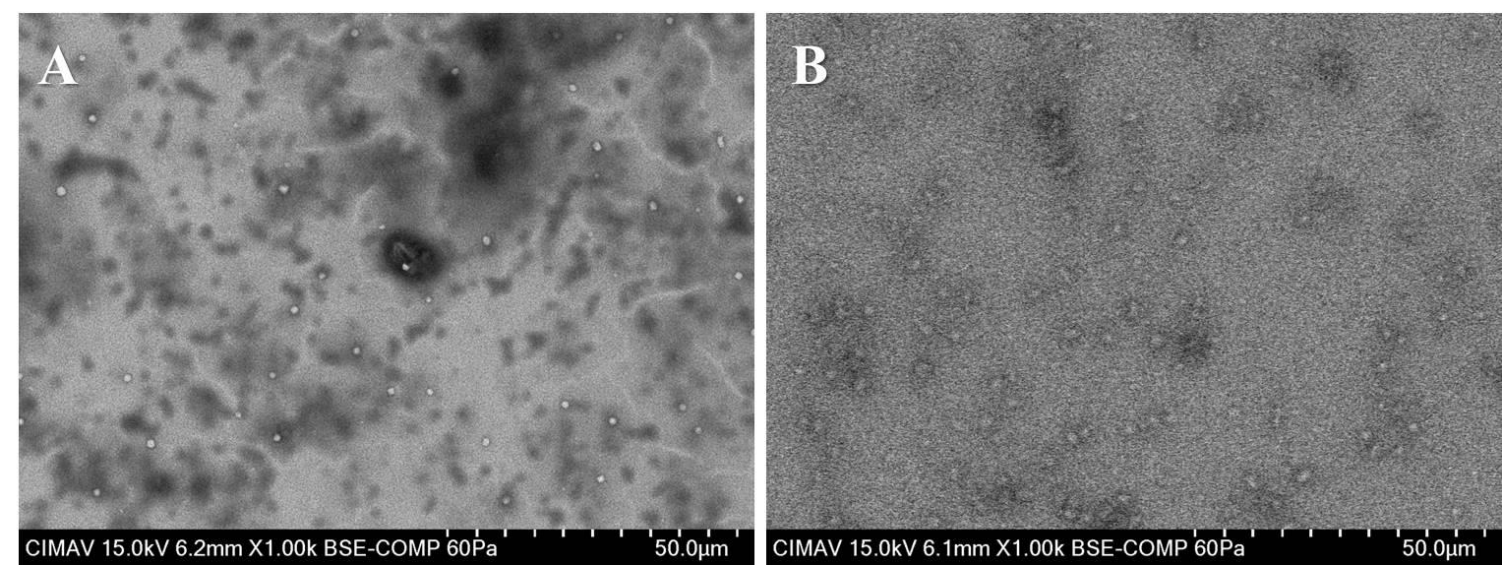

Figure 1. Micrographs at $1,000 \mathrm{X}$ using the Backscattered electrons technique to compare the presence of organic material on the surface of $\mathrm{SnO}_{2}$ thin films inoculated with $S$. aureus before (A) and after (B) exposure to 60 minutes of UV light.
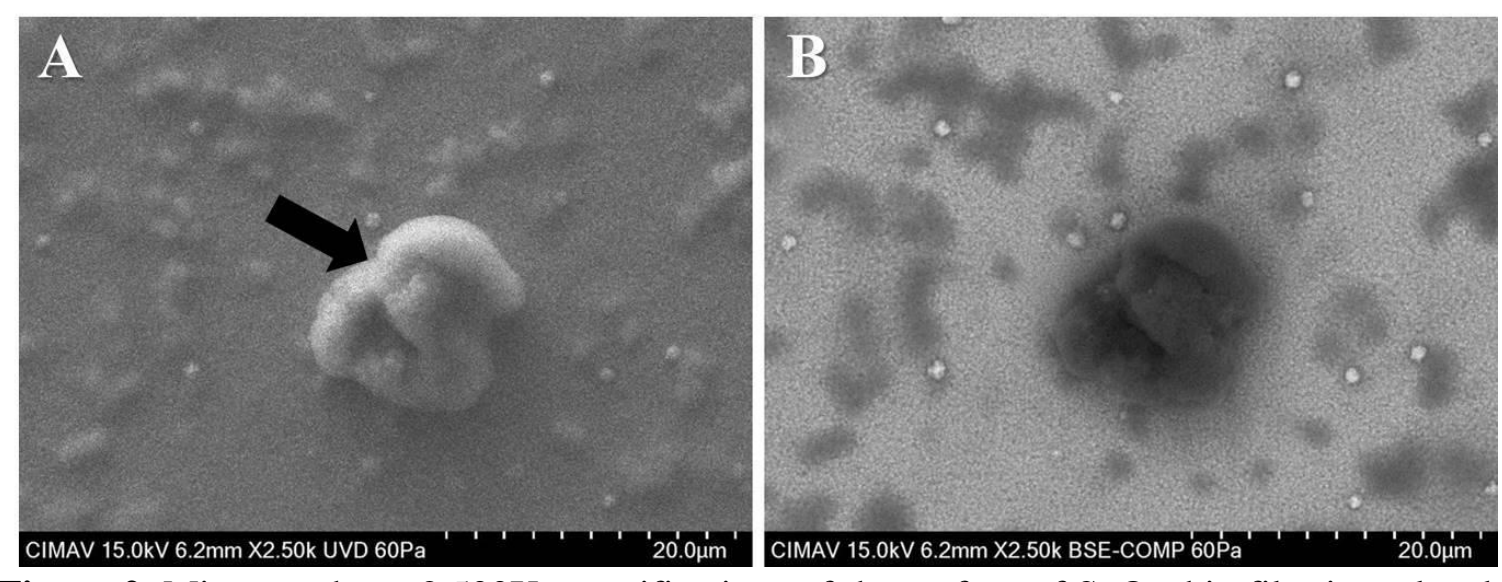

Figure 2. Micrographs at 2,500X magnifications of the surface of $\mathrm{SnO}_{2}$ thin film inoculated with S. aureus. Figure 2A (secondary electrons) shows the morphology of a biofilm (Black arrow) of $S$. aureus. Figure 2B (Backscattered electrons) confirms the organic composition of the biofilm.

\section{References}

[1]Archita Bhattacharjee, M. Ahmaruzzaman. 2015.A novel and green process for the production of tin oxide quantum dots and its application as a photocatalyst for the degradation of dyes from aqueous phase. Journal of Colloid and Interface Science, 448 (2015), 130 - 139

[2] Arzate-Quintana C, Camarillo-Cisneros J, Realyvazquez-Guevara P, Faudoa-Arzate A, \& Rodríguez H. 2020. SEM Study of the Photocatalytic Activity of SnO2 Films Exposed to UV Radiation Against the Human Pathogen C. albicans.Microscopy and Microanalysis, Vol. 26(S2), pp. 1362-1365. doi:10.1017/S1431927620017845

[3] Fakhri, A., Behrouz, S., \& Pourmand, M. (2014). Synthesis, photocatalytic and antimicrobial properties of SnO2, SnS2 and SnO2/SnS2 nanostructure.Journal of Photochemistry and Photobiology B: Biology, (149)45-50.

[4] Friehs E, AlSalka Y, Jonczyk R, Lavrentieva A, Jochums A, Walter JG, Stahl F, Scheper T \&Bahnemanna D. 2016. Toxicity, phototoxicity and biocidal activity of nanoparticles employed in photocatalysis .Journal of Photochemistry and Photobiology C: Photochemistry Reviewsvol 29, pp. 1-28. https://doi.org/10.1016/j.jphotochemrev.2016.09.001 
[5] Kumar M, Kumar-Sarma D, Shubham S, Kumawat M, Verma V, Balabaskaran-Nina P, Devraj JP, Kumar S, Singh B \& Tiwari RR. 2021. Futuristic Non-antibiotic Therapies to Combat Antibiotic Resistance: A Review.Frontiers in microbiology, Vol. 12, pp 1-15. doi: 10.3389/fmicb.2021.609459

[6] Pandiyan, R., Mahalingam, S., \&Ahn, Y.-H. (2019). Antibacterial and photocatalytic activity of hydrothermally synthesized $\mathrm{SnO}_{2}$ doped GO and CNT under visible light irradiation.Journal of Photochemistry \& Photobiology, B: Biology, (191)18-25. 